\title{
ORIENTASI DOMINASI SOSIAL SEBAGAI ALTERNATIF UNTUK MELIHAT SIKAP IMPLISIT TERHADAP SISTEM SOSIAL YANG TIMPANG: ADAPTASI SKALA ORIENTASI DOMINASI SOSIAL 7 (SDO 7 SCALE)
}

\author{
M. Himawan T. Arifianto* \\ Fakultas Psikologi, Universitas Indonesia, Depok \\ *Email: arifianto.himawan@gmail.com
}

\begin{abstract}
Abstrak
Penelitian ini merupakan adaptasi dari konseptualisasi dan pengukuran yang baru dari orientasi dominasi sosial (perbedaan individu pada preferensi untuk hirarki dan ketimpangan berbasis kelompok) yang dinamakan $S D O_{7} S$. Alat ukur $S D O_{7} S$ ini memiliki dua dimensi, yaitu dominasi (SDO-D) dan egalitarian (SDO-E). SDO-D merupakan preferensi untuk sistem dominasi berbasis kelompok, yang mewakili penjelasan bahawa kelompok dengan status tinggi secara langsung menekan kelompok dengan status rendah. SDO-E merupakan preferensi dari sistem ketimpangan berbasis kelompok yang dipertahankan dengan hubungan antara ideologi dan pengaturan sosial yang mendukung adanya hierarki dalam sistem sosial. Adaptasi SDO 7 S ini melibatkan 200 partisipan (69\% perempuan; Musia= 21.6 tahun). Dalam adaptasi alat ukur ini, ditemukan dua item yang bermasalah, yaitu item nomor 1 (SDO1) dan 2 (SDO2). Kedua item ini dikeluarkan dari analisis. Hasil uji reliabilitas menunjukkan bahwa alat ukur adaptasi $S D O_{7} S$ merupakan alat ukur yang reliabel, begitu juga dengan uji validitas yang mengukur bahwa alat ukur adaptasi $\mathrm{SDO}_{7} \mathrm{~S}$ merupakan alat yang valid dalam mengukur orientasi dominasi sosial. Hasil analisis faktor konfirmatori menunjukkan bahwa model dua dimensi dalam orientasi dominasi sosial, yaitu dominasi (SDO-D) dan egalitarian (SDO-E) tidak fit dengan data. Sedangkan model empat faktor dari orientasi dominasi sosial (D-Pro, D-Con, E-Pro, dan E-Con) merupakan model teoretis yang sesuai dengan data. Adaptasi alat ukur $\mathrm{SDO}_{7} \mathrm{~S}$ menunjukkan bahwa pengukuran orientasi dominasi sosial memiliki empat faktor, yang terdiri dari dua dimensi dan masing-masing dua sub-dimensi pada dimensinya.
\end{abstract}

Kata kunci: teori dominasi sosial, orientasi dominasi sosial, dominasi, egalitarian, sistem

\begin{abstract}
This research is an adaptation of new conceptualizations and measurements of social domination orientation (individual differences in preferences for group-based hierarchy and inequality) called SDO7S. This $\mathrm{SDO}_{7} \mathrm{~S}$ measuring instrument has two dimensions, namely dominance (SDO-D) and egalitarian (SDO-E). SDO-D is a preference for group-based domination systems where groups with high status directly suppress groups with low status. SDO-E is a preference of a group-based inequality system that is maintained by the relationship between ideology and social arrangements that support the existence of hierarchies in social systems. This $\mathrm{SDO}_{7} \mathrm{~S}$ adaptation involved 200 participants (69\% women; Mage = 21.6 years). In this measurement adaptation, two invalid items were found, item number 1 (SDO1) and 2 (SDO2). Both of these items were excluded from the analysis. Reliability test results indicate that the SDO7S adaptation measuring instrument is a reliable measuring tool, as well as validity testing that measures that the SDO7Sadaptation measuring instrument is a valid tool in measuring social dominance orientation. The results of the confirmatory factor analysis show that the two-dimensional model in social domination orientation, namely dominance (SDO-D) and egalitarian (SDOE) are not fit with the data. Whereas the four-factor model of social dominance orientation
\end{abstract}


(D-Pro, D-Con, E-Pro, and E-Con) is a theoretical model that fits the data. The adaptation of the $\mathrm{SDO}_{7} \mathrm{~S}$ measuring instrument shows that the measurement of social dominance orientation has four factors, consisting of two dimensions and two sub-dimensions in each dimension.

Keywords: social domination theory, social domination orientation, domination, egalitarian, system

"To understand or to predict behavior, the person and his environment have to be considered as one constellation of interdependent factors"

—Lewin, 1951

\section{Pendahuluan}

Segala sesuatu yang dilakukan oleh manusia, bahkan dalam kesendiriannya, seperti terjadinya proses berpikir, merasakan emosi serta mood, dan tingkah laku sehari-harinya, merupakan refleksi dari norma-norma sosial, ekspektasi sosial, serta kaitan di-antaranya (Hardin \& Higgins, 1996; Jost \& van der Toorn, 2012, p.313). Hal ini "membatasi" tingkah laku manusia menjadi suatu hal yang dapat diprediksi. Manifestasinya dapat kita lihat pada sistem sosial yang ada di kehidupan manusia. Misalnya, prasangka yang mengangga kaukasian (kulit putih; whites) lebih baik dibandingkan dengan negro (kulit hitam; blacks).

Sistem sosial yang ada di masyarakat berjalan berdasarkan status sosial yang dimiliki oleh masing-masing anggotanya (Pratto, Liu, Levin, Sidanius, Shih, Bachrach, \& Hegarty, 2000). Status sosial ini terbentuk dari kriteria serta karakteristik umum yang dimiliki oleh anggota kelompok, yang kemudian kedua hal itu menjadi suatu bentuk identitas yang unik pada tiap kelompok dan merepresentasikan keseluruhan anggota-nya. Kumpulan karakteristik dari kelompok inilah yang menjadi dasar untuk penentuan apa yang "baik" dan apa yang "buruk" pada setiap pengaturan sosial, dan kelompok yang dominan yang menentukan orientasi dari kedua hal itu.
Yang biasanya terjadi adalah apa yang dianggap "baik" berpotongan dengan karakteristik dari kelompok yang dominan.

Pada dasarnya terdapat tiga hal yang umum terjadi pada sistem sosial (Pratto dkk., 2000), yaitu: (1) perbedaan individu pada preferensi terhadap ketimpangan berbasis kelompok dapat diukur karena sistem sosial memiliki pola hegemoni, yaitu kelompok yang dominan biasanya berkuasa dengan menentukan berbagai pengaturan sosial; (2) ODS memiliki hubungan yang positif dengan sikap yang mendukung hegemoni kelompok dan memiliki hubungan yang negatif dengan sikap yang mendukung kelompok yang tertindas atau egalitarian; serta (3) pria cenderung lebih tinggi ODSnya dibandingkan dengan perempuan.

Konstruk orientasi dominasi sosial (ODS) berasal dari fenomena di masyarakat modern sekarang yang memiliki sistem hirarki berdasarkan kelompok, dengan salah satu atau beberapa kelompok memiliki kekuatan dan sumber daya yang timpang bila dibandingkan dengan kelompok lain (Pratto, Sidanius, Stallworth, \& Malle, 1994; Sidanius \& Pratto, 1999). Orientasi dominasi sosial (ODS) adalah sebuah orientasi atau kecenderungan yang umum untuk menginginkan kondisi ketimpangan dan dominasi dari satu pihak terhadap pihak lain, di luar dari implikasinya pada hirarki dalam kelompok itu sendiri (Pratto, Sidanius, \& Levin, 2006). Kelompok yang mendominasi akan lebih termotivasi untuk mempertahankan posisi dominan mereka dengan mengadopsi suatu sistem kepercayaan dan ideologi yang men- 
dukung ketimpangan sosial.

Beberapa penelitian mengenai ketimpangan menemukan bahwa anggota dari kelompok yang memiliki status yang tinggi akan lebih cenderung mendukung ketimpangan sosial yang sedang terjadi (Morisson, Fast, \& Ybarra, 2008), dan sikap ini berimplikasi pada skor orientasi dominasi sosial (ODS) yang tinggi.

Orientasi dominasi sosial juga dapat digunakan untuk memprediksi sikap sosial dan politik. Dengan memahami orientasi dominasi sosial orang di sebuah masyarakat, kita dapat memprediksi pilihan dan preferensi mereka dalam pemilu dan terhadap kebijakan-kebijakan sosial. Di sisi lain, dengan mengetahui orientasi dominasi sosial yang dimiliki pemimpin atau pengambil kebijakan, kita dapat memprediksi kebijakan yang akan diambilnya, apakah mendukung adanya hierarki kelompok (yang cenderung diskriminatif) ataukah tidak. Yang terpenting, dengan mengetahui orientasi dominasi sosial individu atau sekelompok orang, kita dapat menentukan cara terbaik dalam melakukan intervensi untuk mengurangi prasangka dan diskriminasi.

Kepercayaan dan ideologi diciptakan manusia untuk membantu hidup manusia agar lebih mudah diterima dan dijelaskan. Dengan sistem itu ditawarkan suatu bentuk penjelasan dan pemahaman mengenai kondisi sosial yang tidak sempurna, atau bahkan merugikan (Jost \& Banaji, 2004; Jost, Banaji, \& Nosek, 2004; Jost dkk., 2014). Salah satu kekuatan lain yang mempertahankan dominasi sosial adalah ideologi. Ideologi menjadi suatu acuan bagi orang-orang untuk bertingkah laku seakan ideologi tampak sebagai sumber dari kebenaran. Ini dapat terjadi karena beberapa proses psikologis sosial (e.g. self-fulfilling prophecy, cognitive biases) mempengaruhi jalannya pengambilan keputusan, yang juga menjadi salah satu alasan mengapa ideologi dianut oleh anggota pada masing-masing kelompok tempat ideologi itu didengungkan (Moscovici, 1984; Pratto dkk., 2000).
Teori dominasi sosial dapat diaplikasikan dalam berbagai budaya karena teori ini memiliki postulat bahwa ideologi dapat digunakan untuk menguatkan atau mengurangi efek dari hierarki sosial selama kondisi itu terhubung dengan nilai-nilai utama dalam budaya dan secara umum diketahui oleh orang-orang di dalamnya. Oleh karena itu, ideologi memiliki fungsi sebagai mediator antara berbagai kondisi psikologis, situasi sosial, dan struktur sosial, terutama dalam mempertahankan atau menjaga distribusi kekuatan antara kelompok yang berada pada sistem sosial. Oleh karena itu, instrumen untuk mengukur orientasi dominasi sosial yang baik menjadi kebutuhan yang tidak terelakkan.

Teori Dominasi Sosial. Salah satu teori yang dapat menjelaskan fenomena prasangka dan diskriminasi antar kelompok adalah teori dominasi sosial (Social Dominance Theory; SDT; Sidanius \& Pratto, 1999). Menurut teori ini, setiap orang dan kelompok dalam masyarakat, secara inheren, memiliki kecenderungan untuk membentuk hierarki dalam masyarakat. Sebagian besar bentuk penindasan dan diskriminasi, seperti etnosentrisme, seksisme, rasisme, dan nasionalisme merupakan usaha untuk membangun dan mempertahankan struktur hierarkis berbasis kelompok yang terbentuk dalam masyarakat. Berdasarkan teori dominasi sosial, determinan utama yang mendorong timbulnya prasangka dan diskriminasi antar kelompok adalah orientasi dominasi sosial. Level analisis teori dominasi sosial berada pada ranah proses antar kelompok (intergroup process) dalam ranah psikologi sosial.

Pada awalnya, teori dominasi sosial dikembangkan untuk menjelaskan fenomena rasisme, diskriminasi dan stereotipe melalui penjelasan mekanisme proses intrapersonal yang ada pada individu. Oleh karena itu, struktur dari teori dominasi sosial memiliki jangkauan pada tiga hal, yaitu dinamika kepribadian; nilai dasar, kecemasan, dan kepercayaan indi- 
vidu; serta proses kognitif individu (Sidanius \& Pratto, 1999).

Postulat dasar teori dominasi sosial adalah penindasan, diskriminasi, dan prasangka antar kelompok merupakan suatu cara bagi struktur masyarakat untuk mengatur sistem tatanan sosial tersebut dengan cara membentuk hirarki berdasarkan kelompok-kelompok yang ada dalam sistem tersebut. Terdapat tiga prinsip utama yang mendasari teori dominasi sosial (Sidanius \& Pratto, 2012), yaitu: (1) Sistem sosial manusia adalah sistem yang tangguh, dalam artian sulit sekali untuk dibubarkan atau dihancurkan karena cenderung beradaptasi dan berubah seiring berjalannya waktu; (2) Berbagai bentuk dari penindasan kelompok (e.g. seksisme, rasisme, nasionalisme, etnosentrisme, dll.) seharusnya dilihat sebagai bentuk usaha untuk membentuk hirarki sosial berbasis "kekuatan" kelompok; serta (3) Tingkatan dari hirarki sosial berbasis kelompok dalam masyarakat adalah hasil akhir dari interaksi antara tingkatan berlapis dari usaha untuk mendukung dan mempertahankan hirarki dalam sistem sosial masyarakat.

Teori dominasi sosial juga menekankan bahwa sikap yang dimiliki individu terhadap persebaran ideologiideologi sosial, kebijakan terkait kelompok-kelompok sosial, serta mengenai kelompok sosial itu sendiri, akan terpengaruhi oleh seberapa besar preferensi individu tersebut terhadap dominasi kelompok dan ketimpangan sosial secara umum (Sidanius \& Pratto, 2012), hal ini disebut juga sebagai orientasi terhadap dominasi sosial (social dominance orientation; SDO, Pratto dkk., 1994). Pengukuran mengenai orientasi dominasi sosial ini akan menjadi standar empiris untuk memahami bagaimana ideologiideologi yang ada menjadi sumber legitimasi untuk menjustifikasi status quo, terutama pengaturan dan hirarki sosial.

Orientasi dominasi sosial (ODS) dapat diartikan sebagai perbedaan individual yang menggambarkan nilai dan sikap seseorang terhadap kondisi nonegaliter dan hierarkis di antara kelompokkelompok sosial. Teori dominasi sosial mendalilkan bahwa orang dengan orientasi dominasi sosial yang tinggi akan cenderung mendukung ideologi dan kebijakan yang meningkatkan atau menjaga keberadaan hierarki, sedangkan mereka dengan orientasi dominasi sosial rendah akan cenderung mendukung ideologi dan kebijakan yang melemahkan keberadaan hierarki. Orang dengan orientasi dominasi sosial tinggi adalah mereka yang percaya bahwa masyarakat terbagi menjadi dua struktur, yaitu kelompok dengan status tinggi dan rendah. Kelompok yang berstatus tinggi adalah pemenang, memiliki kekuatan dan semua nilai positif. Melalui berbagai penelitian pada berbagai sampel, konteks, dan negara, orientasi dominasi sosial terbukti memiliki hubungan dengan banyak hal, seperti rasisme, seksisme, dukungan terhadap agresi (perang), prasangka, pemilihan karir/peran, anti-egalitarian dan tingkah laku diskriminasi.

Meskipun terdapat beragam penemuan terkait ODS ini, masih belum ada penjelasan implikasi ODS pada posisi relatif dari suatu kelompok merupakan hal fluktuatif yang tidak terlalu stabil (Morisson dkk., 2008). Hubungan antara status dan kekuatan dapat berfluktuasi tergantung dari kondisi sosial dan ekonomi yang ada, dengan kondisi yang membuat suatu kelompok merasa terintimidasi oleh kelompok lain yang mengganggu kemaslahatan posisi kelompok mereka, situasi ini disebut juga sebagai ancaman posisi antar kelompok (Morisson dkk., 2008). Ancaman terhadap posisi kelompok ini ditemukan memiliki pengaruh kepada munculnya prasangka (Zárate, Garcia, Garza, \& Hitlan, 2004) dan lebih menginginkan pengaturan yang mendukung kondisi mereka sekarang (status quo), yatu keadaan yang lebih familiar untuk mereka saat ini meskipun memiliki indikasi ketimpangan. Berdasarkan hal ini, ODS memiliki fungsi untuk melindungi 
posisi dan sumber daya ingroup terhadap sebuah situasi yang mengancam, terutama jika situasi tersebut membutuhkan perubahan.

Pengukuran ODS Sebelumnya: The New Social Dominance Orientation 7 Scale $\left(\mathrm{SDO}_{7}\right.$ Scale). Skala untuk mengukur orientasi dominasi sosial (Social Dominance Orientation Scale; Skala ODS) telah mengalami beberapa kali pengembangan atau revisi. Skala ODS pertama kali dikembangkan oleh Pratto dkk. (1994). Skala tersebut dikenal dengan skala $\mathrm{SDO}_{5}$ yang dari 14 item dan bersifat unidimensional. Namun demikian, para peneliti menduga bahwa skala $\mathrm{SDO}_{5}$ kemungkinan besar terdiri dari dua dimensi yang sangat berkaitan namun berbeda. Oleh karena itu, pada tahun 2012, Ho dkk. merevisi skala $\mathrm{SDO}_{5}$ dan menghasilkan skala $\mathrm{SDO}_{6}$ yang terdiri dari 16 item pernyataan dalam dua dimensi berbeda. Satu dimensi merefleksikan dukungan atas keberadaan dominasi hierarkis dalam masyarakat (disebut SDO-D), dan satu dimensi merefleksikan dukungan terhadap kesetaraan kelompok dalam masyarakat (disebut SDO-E). Lebih lanjut, dua dimensi ternyata belum cukup untuk menggambarkan konstruk yang diukur oleh skala SDO. Ho dkk. (2015) melakukan studi psikometri dan memperoleh hasil yang menunjukkan bahwa skala SDO dengan empat faktor merupakan skala yang paling fit. Skala hasil dari proses adaptasi instrumen dengan berdiskusi dengan akademisi lainnya yang dianggap ahli dalam teori dominasi sosial dan berpengalaman dengan instrumen psikologis. Peran ahli adalah mengkonsolidasikan semua versi kuesioner dan mengembangkannya menjadi sebuah versi prefinal dari kuesioner untuk pengujian lapangan (Beaton dkk., 2000). Rincian dari langkah-langkah yang dilakukan dalam proses adaptasi $\mathrm{SDO}_{7} \mathrm{~S}$ ini akan dijabarkan pada bagian selanjutnya.

Partisipan Penelitian. Berdasarkan definisi dari Erikson dan Tedin (2015) tersebut dinamakan skala $\mathrm{SDO}_{7}$ yang terdiri dari dua dimensi (SDO-D dan SDO-E) dan dua sub dimensi (pro-trait dan con-trait). pro-trait dan con-trait merefleksikan arah dari item pernyataan, dengan skor yang tinggi pada pro-trait mengindikasikan level SDO yang tinggi, sedangkan skor yang tinggi pada con-trait mengindikasikan level SDO yang rendah.

Dalam penelitian ini, peneliti melakukan adaptasi terhadap skala $\mathrm{SDO}_{7}$ yang telah dianalisis oleh Ho dkk. (2015; Appendix A). Hasil dari confirmatory factor analysis (CFA) dan analisis validitas kriteria yang dilakukan Ho dkk. (2015) membuktikan bahwa keempat faktor dalam skala $\mathrm{SDO}_{7}$ merupakan faktor yang berbeda dan memprediksi ranah masingmasing dengan tepat.

\section{Metode Penelitian}

Proses adaptasi instrumen $\mathrm{SDO}_{7} \mathrm{~S}$ dimulai dengan menerjemahkan alat ukur ini ke Bahasa Indonesia. Dengan bantuan dari penerjemah yang memiliki kemampuan berbahasa Inggris dan Indonesia yang baik, hasil terjemahan dari kedua penerjemah ini disintesis. Hasis sistensis ini kemudian diterjemahkan kembali ke Bahasa Inggris dengan menggunakan penerjemah yang berbeda. Hal ini dilakukan untuk melihat apakah terjadi pergeseran makna ketika diterjemahkan. Ketika hasil terjemahan $\mathrm{SDO}_{7} \mathrm{~S}$ sudah sesuai dengan instrumen aslinya, langkah selanjutnya adalah mengecek mengenai opini publik, hanya orang dewasa sajalah yang terhitung mampu untuk mengemukakan opini publik. Berdasarkan definisi tersebut, kriteria partisipan/responden yang dibutuhkan adalah mereka yang secara sah oleh Indonesia sudah dianggap dewasa dengan kepemilikan Kartu Tanda Penduduk (KTP) atau mereka yang berusia 17 tahun dan sudah bisa ikut dalam pemilihan umum. Partisipan penelitian ini direkrut secara online sebanyak 200 orang $(69 \%$ perempuan; $M_{\text {usia }}=21,6$ tahun) menggunakan Google Form dari Google. Partisipan mengisi data demografis dan 
alat ukur $S D O_{7} S$ yang diadaptasi, partisipan yang tidak sesuai dengan kriteria dikeluarkan dari analisis $\left(n=2 ; M_{\text {usia }}=\right.$ 16 tahun).

Penerjemahan $\mathrm{SDO}_{7} \mathrm{~S}$ ke Bahasa Indonesia. Tahap pertama dari proses adaptasi alat ukur SDO adalah dengan menerjamahkan SDO versi asli dalam bahasa Inggris ke dalam bahasa Indonesia. Proses penerjemahan dilakukan oleh dua orang penerjemah independent dengan kemampuan Bahasa Inggris baik. Salah satu penerjemah punya memiliki pengetahuan teori dominasi social.

Menerjemahkan Kembali ke Bahasa Inggris. Untuk memastikan kesepadanan semantik atau makna dari hasil sintesis penerjemahan, langkah selanjutnya yang dilakukan adalah dengan memahami konsep teoritis alat ukur yang diterjemahkan.

\section{Hasil Penelitian}

Hasil dari penelitian ini akan dijabarkan pada bagian hasil uji reliabilitas dan hasil uji validitas. Hasil analisis faktor eksploratori dan konfirmatori merupakan bagian dari hasil uji validitas karena keduanya termasuk sebagai metode untuk menguji validitas alat ukur.

Hasil Uji Reliabilitas. Salah satu persyaratan suatu alat ukur dianggap baik adalah jika alat ukur itureliabel (andal). Reliabilitas adalah proporsi dari true variance dalam skor tes yang didapat (Guilford, 1954). Cohen dan Swerdlik (2010) menyatakan bahwa terdapat berbagai metode dalam mengukur reliabilitas suatu tes. Yang digunakan dalam penelitian ini adalah metode konsitensi internal yaitu reliabilitas alat ukur didapatkan dari korelasi antara item dalam alat ukur itu sendiri. Reliabilitas dapat diekspresikan melalui koefisien korelasi karena seluruh tipe reliabilitas menekankan pada konsistensi antara dua set skor yang independen. Kemudian menurut Anastasi dan Urbina (1997) reliabilitas yang baik dari suatu alat ukur jatuh pada korelasi 0,80 . menerjemahkan kembali (back translation) hasil sintesis ke dalam bahasa Inggris (tabel 2). Menjamin kesetaraan makna menjadi aspek terpenting dalam penerjemahan (Cruz, Padilla, \& Agustin 2000). Proses penerjemahan kembali ini juga merupakan salah satu proses pengecekan validitas untuk memastikan bahwa versi terjemahannya mencerminkan konten item yang sama dengan versi aslinya (Beaton dkk., 2000).

Dalam melakukan proses penerjemahan kembali, peneliti menggunakan jasa dua penerjemah. Kriteria pertama yang ditetapkan dalam memilih penerjemah adalah seseorang yang menguasai dua bahasa (bilingual), yaitu bahasa Inggris dan bahasa Indonesia. Kriteria kedua adalah penerjemah tidak Peneliti menggunakan metode Cronbach's alpha yang termasuk dalam metode konsistensi internal dalam menguji reliabilitas alat ukur ini. Caranya adalah mengkorelasikan seluruh item dalam alat ukur menggunakan rumus dari Cronbach's alpha. Peneliti melakukan dua kali analisis untuk dua kali pengukuran.

Pada analisis reliabilitas pengukuran pertama, nilai Cronbach's alpha melebihi batas yang ditentukan oleh Anastasi dan Urbina (1997), yaitu sebesar 0,839, skor ini mengindikasikan bahwa pada pengukuran pertama, adaptasi alat ukur $\mathrm{SDO}_{7} \mathrm{~S}$ memiliki reliabilitas yang baik. Pada pengukuran kedua, skor reliabilitas naik menjadi 0,858 (lihat Tabel 2). Secara keseluruhan, koefisien reliabilitas dari alat ukur adaptasi $\mathrm{SDO}_{7} \mathrm{~S}$ adalah 0,898 , yang mengindikasikan bahwa adaptasi alat ukur $\mathrm{SDO}_{7} \mathrm{~S}$ untuk pengukuran kedua memiliki reliabilitas yang baik karena $89,8 \%$ dari varians adalah true score, dan 10,2\% merupakan error.

Hasil Uji Validitas. Validitas dari suatu tes menekankan pada apa yang diukur oleh tes dan seberapa baik tes itu mengukurnya (Anastasi \& Urbina, 1997). Terdapat tiga jenis validitas, yaitu content 
Tabel 1. Item-Item Adaptasi SDO 7 S (Kedua)

\begin{tabular}{|c|c|}
\hline Item & Deskripsi \\
\hline SDO1 & $\begin{array}{l}\text { Beberapa kelompok seharusnya tetap berada pada status sosial mereka mas- } \\
\text { ing-masing }\end{array}$ \\
\hline SDO2 & $\begin{array}{l}\text { Mungkin merupakan hal yang baik jika terdapat kelompok tertentu yang ber- } \\
\text { status sosial tinggi dan kelompok lainnya memiliki status sosial rendah }\end{array}$ \\
\hline SDO3 & $\begin{array}{l}\text { Masyarakat yang ideal terdiri atas beberapa kelompok yang berstatus sosial } \\
\text { lebih tinggi dan kelompok lain berstatus sosial lebih rendah }\end{array}$ \\
\hline SDO4 & Beberapa kelompok lebih rendah daripada kelompok-kelompok lainnya \\
\hline SDO5* & $\begin{array}{l}\text { Kelompok yang status sosialnya rendah memiliki hak yang setara dengan ke- } \\
\text { lompok yang status sosialnya tinggi }\end{array}$ \\
\hline SDO6* & Seharusnya tidak ada satu pun kelompok yang dominan dalam masyarakat \\
\hline $\mathrm{SDO}^{*}$ & $\begin{array}{l}\text { Kelompok-kelompok dengan status sosial rendah tidak seharusnya tetap di } \\
\text { posisi mereka }\end{array}$ \\
\hline SDO8* & $\begin{array}{l}\text { Dominasi suatu kelompok atas kelompok lain adalah sebuah prinsip yang bu- } \\
\text { ruk }\end{array}$ \\
\hline SDO9 & Kita seharusnya tidak mendorong kesetaraan kelompok \\
\hline SDO10 & $\begin{array}{l}\text { Kita seharusnya tidak mengusahakan agar semua kelompok memiliki kualitas } \\
\text { hidup yang sama }\end{array}$ \\
\hline SDO11 & Merupakan sebuah ketidakadilan membuat setiap kelompok menjadi setara \\
\hline SDO12 & Kesetaraan status antar kelompok tidak seharusnya menjadi tujuan utama kita \\
\hline SDO13* & $\begin{array}{l}\text { Kita harus berusaha memberikan kesempatan yang setara pada semua ke- } \\
\text { lompok masyarakat dalam meraih keberhasilan }\end{array}$ \\
\hline SDO14* & $\begin{array}{l}\text { Kita harus melakukan apapun yang kita mampu untuk menyetarakan kondisi } \\
\text { kelompok yang berbeda-beda }\end{array}$ \\
\hline SDO15* & $\begin{array}{l}\text { Sebesar apapun upaya yang dibutuhkan, kita harus berusaha memastikan } \\
\text { bahwa semua kelompok memiliki kesempatan yang sama dalam hidup }\end{array}$ \\
\hline SD016* & Kesetaraan antar kelompok seharusnya menjadi cita-cita kita \\
\hline
\end{tabular}

validity (validitas isi), criterion validity (validitas kriterion), dan construct validity (validitas konstruk). Validitas isi digunakan untuk pemeriksaan isi dari tes untuk menentukan apakah tes merepresentasikan sampel dari domain tingkah laku yang hendak diukur, dalam hal ini berarti apakah alat ukur ini merepresentasikan orientasi dominasi sosial. Validitas konstruk dari suatu tes merupakan sejauh mana suatu tes dapat dikatakan mampu mengukur konstruk teoritis atau trait. Validitas dari suatu tes diekpresikan dengan menggunakan hasil dari korelasi skor tes dan kriterion yang digunakan (Anasatasi \& Urbina, 1997). Koefisien validitas yang terbaik untuk proses seleksi adalah 0,35 ke atas.
Tabel 2.Hasil Uji Reliabilitas

\begin{tabular}{lcc}
\hline & $\boldsymbol{\alpha}$ & Jumlah Item \\
\hline $\begin{array}{l}\text { Pengukuran } \\
\text { Pertama }\end{array}$ & 0,833 & 16 \\
$\begin{array}{l}\text { Pengukuran } \\
\text { Kedua }\end{array}$ & 0,858 & 16 \\
SDO Total & 0,898 & 16 \\
\hline
\end{tabular}

Dalam pengukuran, peneliti menemukan bahwa terdapat dua item yang bermasalah, yaitu item nomor 1 dan 2 (Tabel 3). Berdasarkan standar yang ditentukan oleh Anastasi dan Urbina (1997), kedua item ini memiliki skor korelasi yang lebih rendah daripada 0,35. Hal ini mengindikasikan bahwa kedua 
Tabel 3. Korelasi per Item dengan Skor Total

\begin{tabular}{lcc}
\hline & CrIT & $\alpha$ \\
\hline SDO1 & 0,090 & 0,906 \\
SDO2 & 0,316 & 0,900 \\
SDO3 & $\mathbf{0 , 5 0 1}$ & $\mathbf{0 , 8 9 4}$ \\
SDO4 & $\mathbf{0 , 4 7 6}$ & $\mathbf{0 , 8 9 5}$ \\
SDO5 & $\mathbf{0 , 7 3 1}$ & $\mathbf{0 , 8 8 5}$ \\
SDO6 & $\mathbf{0 , 6 3 0}$ & $\mathbf{0 , 8 8 9}$ \\
SDO7 & $\mathbf{0 , 5 3 1}$ & $\mathbf{0 , 8 9 3}$ \\
SDO8 & $\mathbf{0 , 6 3 0} \mathbf{0 , 8 8 9}$ \\
SDO9 & $\mathbf{0 , 5 1 6} \mathbf{0 , 8 9 3}$ \\
SDO10 & $\mathbf{0 , 4 9 0} \mathbf{0 , 8 9 4}$ \\
SDO11 & $\mathbf{0 , 5 4 1}$ & $\mathbf{0 , 8 9 2}$ \\
SDO12 & $\mathbf{0 , 4 9 1} \mathbf{0 , 8 9 4}$ \\
SDO13 & $\mathbf{0 , 7 6 9}$ & $\mathbf{0 , 8 8 3}$ \\
SDO14 & $\mathbf{0 , 7 1 3}$ & $\mathbf{0 , 8 8 6}$ \\
SDO15 & $\mathbf{0 , 7 7 2}$ & $\mathbf{0 , 8 8 3}$ \\
SDO16 & $\mathbf{0 , 7 0 9}$ & $\mathbf{0 , 8 8 6}$ \\
\hline
\end{tabular}

item ini tidak mampu untuk merepresentasikan orientasi dominasi sosial.

Peneliti juga membandingkan korelasi antar item dengan setiap item pada dimensinya. Peneliti menggunakan metode inter-item consistency (rIT) sebagai acuran utama untuk melakukan uji item, yang disebut oleh Cohen dan Swerdlik (2009) sebagai item-reliability index. Inter-item consistency ini dilakukan dengan mengkorelasikan skor tiap item pada alat ukur dengan total skor item alat ukur itut tanpa memasukkan skor dari item yang dianalisis, hal ini dilakukan agar tidak terjadi overestimate pada hasil korelasi. Setelah dikorelasikan terdapat skor indeks yang disebut dengan rIT. rIT merupakan teknik prioritas utama dalam penentuan item alat ukur dipertahankan atau dibuang. Peneliti juga menggunakan metode coefficient alpha dari Cronbach untuk memberikan gambaran apakah bila suatu item dihilangkan akan mempengaruhi reliabiltas dari alat ukur atau tidak. Hal ini digunakan sebagai bahan pertimbangan untuk mempertahankan atau membuang item. Penjabarannya ada pada Tabel 4 dan 8 .

Hasil pada Tabel 4 menjadi bahan pertimbangan bagi peneliti untuk menganalisis item-item mana saja yang dipertahankan dan mana yang dibuang pada pengukuran pertama dari adaptasi $\mathrm{SDO}_{7} \mathrm{~S}$. Pada pengukuran pertama, terdapat dua item yang bermasalah, yaitu item nomor 1, 4, dan 7. Pada dimensi pro-dominance, item 1 dan 4 memiliki hubungan yang rendah meskipun berada pada satu dimensi, keduanya tidak memiliki hubungan yang signifikan, sedangkan item nomor 7 tidak menggambarkan dimensi con-dominance karena tidak memiliki hubungan yang signifikan dengan item-item lainnya $(5,6$, dan 8$)$ yang berada pada dimensi yang sama. Hasil uji validitas juga konsisten dengan rIT ini, bahwa item yang bermasalah adalah item nomor 1 dan 7. Meskipun item nomor 4 juga bermasalah dalam rIT, dengan melihat hasil uji validitas, diketahui bahwa masalah terdapat dalam item nomor 1, bukan nomor 4. Berdasarkan hal ini, peneliti memutuskan bahwa item nomor 1 dan nomor 7 perlu mengalami revisi.

Pada pengukuran kedua, peneliti menemukan bahwa hanya item 1 (SDO1) yang bermasalah karena tidak memiliki hubungan dengan item-item lainnya pada dimensi yang sama. Namun melihat hasil uji konsistensi internal, perlu dipertimbangkan juga untuk merevisi item 2 (SDO2). Berdasarkan hasil ini, secara umum item yang perlu direvisi adalah item nomor 1 dan nomor 2 (SDO1 dan SDO2).

Hasil Analisis Faktor Eksploratori. Pada tahap pertama, peneliti menggunakan analisis faktor eksploratori (EFA) untuk mengidentifikasi dimensi dari orientasi dominasi sosial. Himpunan data dalam analisis faktor eksploratori (EFA) dianalisis dengan menggunakan pilihan principal components (komponen utama), dengan menggunakan rotasi orthogonal 
Tabel 4. Analisis Faktor Eksploratori Pengukuran Pertama

\begin{tabular}{lrrrr}
\hline & \multicolumn{4}{c}{ Komponen } \\
\cline { 2 - 5 } & Con-Egalitarian & Pro-Dominance & Pro-Egalitarian & Con-Dominance \\
\hline [SDO1] Old & 0,130 & $\mathbf{0 , 2 6 3}$ & 0,511 & $-0,426$ \\
[SDO2] Old & $-0,028$ & $\mathbf{0 , 7 7 1}$ & 0,268 & 0,063 \\
[SD03] Old & 0,234 & $\mathbf{0 , 8 4 2}$ & 0,123 & 0,071 \\
[SDO4] Old & 0,190 & $\mathbf{0 , 7 7 1}$ & $-0,065$ & 0,032 \\
[SDO5] Old & 0,598 & 0,063 & 0,135 & $\mathbf{0 , 2 1 1}$ \\
[SDO6] Old & 0,146 & 0,189 & 0,066 & $\mathbf{0 , 7 9 1}$ \\
[SDO7] Old & $-0,070$ & 0,481 & 0,142 & $\mathbf{0 , 2 2 1}$ \\
[SD08] Old & 0,178 & 0,070 & 0,248 & $\mathbf{0 , 5 4 9}$ \\
[SD09] Old & 0,148 & 0,004 & $\mathbf{0 , 7 4 9}$ & 0,084 \\
[SDO10] Old & 0,226 & 0,072 & $\mathbf{0 , 7 5 2}$ & 0,081 \\
[SD011] Old & 0,216 & 0,201 & $\mathbf{0 , 5 3 1}$ & 0,242 \\
[SD012] Old & 0,044 & 0,252 & $\mathbf{0 , 6 2 7}$ & 0,395 \\
[SD013] Old & $\mathbf{0 , 7 8 4}$ & 0,057 & 0,191 & $-0,069$ \\
[SD014] Old & $\mathbf{0 , 5 5 0}$ & 0,169 & 0,109 & 0,441 \\
[SD015] Old & $\mathbf{0 , 8 0 5}$ & 0,036 & 0,145 & 0,101 \\
[SD016] Old & $\mathbf{0 , 5 2 9}$ & 0,162 & 0,196 & 0,511 \\
\hline
\end{tabular}

Tabel 5. Analisis Faktor Eksploratori Pengukuran Kedua

\begin{tabular}{lrrrr}
\hline & \multicolumn{4}{c}{ Komponen } \\
\cline { 2 - 5 } & Con-Egalitarian & Pro-Egalitarian & Pro-Dominance & Con-Dominance \\
\hline SDO1 & 0,002 & $-0,103$ & $\mathbf{0 , 1 4 2}$ & $-0,710$ \\
SDO2 & $-0,073$ & 0,170 & $\mathbf{0 , 7 8 8}$ & $-0,013$ \\
SDO3 & $-0,239$ & 0,224 & $\mathbf{0 , 8 4 2}$ & 0,014 \\
SDO4 & $-0,147$ & $-0,051$ & $\mathbf{0 , 7 4 4}$ & $-0,305$ \\
SDO5 & 0,338 & $-0,123$ & $-0,135$ & $\mathbf{0 , 6 6 7}$ \\
SD06 & 0,258 & $-0,341$ & 0,226 & $\mathbf{0 , 6 6 7}$ \\
SDO7 & 0,397 & $-0,203$ & $-0,293$ & $\mathbf{0 , 3 5 5}$ \\
SDO8 & 0,181 & $-0,277$ & $-0,116$ & $\mathbf{0 , 6 7 7}$ \\
SD09 & $-0,064$ & $\mathbf{0 , 7 1 3}$ & 0,225 & $-0,213$ \\
SD010 & $-0,132$ & $\mathbf{0 , 8 3 0}$ & $-0,104$ & $-0,006$ \\
SD011 & 0,006 & $\mathbf{0 , 6 2 1}$ & 0,360 & $-0,123$ \\
SD012 & 0,011 & $\mathbf{0 , 8 3 5}$ & 0,096 & $-0,102$ \\
SD013 & $\mathbf{0 , 6 9 2}$ & $-0,251$ & $-0,316$ & 0,374 \\
SD014 & $\mathbf{0 , 8 5 2}$ & $-0,055$ & 0,066 & 0,208 \\
SD015 & $\mathbf{0 , 7 9 6}$ & $-0,105$ & $-0,296$ & 0,264 \\
SD016 & $\mathbf{0 , 8 6 5}$ & 0,113 & $-0,122$ & $-0,019$ \\
\hline
\end{tabular}

(varimax). Kriteria factor loading pada tiap item yang baik adalah 0.4 , item yang memiliki factor loading di bawah batas ini bukanlah item yang baik sebagai manifestasi dari variabel laten.
Sesuai dengan teori Dominasi Sosial (Sidanius \& Pratto, 1999) dan konsepsi baru dari Ho dkk. (2015), orientasi dominasi sosial memiliki empat dimensi: Pro-dominance, con-dominance, proegalitarian, dan con-egalitarian. Hal ini 
juga sejalan dengan penemuan dari konstruksi alat ukur $\mathrm{SDO}_{7} \mathrm{~S}$ (Ho dkk., 2015) yaitu orientasi dominasi sosial memiliki empat dimensi seperti yang sudah disebutkan sebelumnya. Penjabarannya ada pada Tabel 4 untuk pengukuran pertama, dan pada Tabel 5 untuk pengukuran kedua.

Hasil Analisis Faktor Konfirmatori. Data pada penelitian ini dianalisis dengan Structural Equation Modeling (SEM) menggunakan paket Lavaan pada versi $R$ 3.4.3. Peneliti menggunakan estimator maximum likelihood dengan robust standard errors dan uji skala statistik Satorra-Bentler yang digunakan jika data tidak terdistribusi secara normal. Kriteria cut-off yang digunakan untuk menilai kecocokan (fit) antara model yang dihipotesiskan dan data riil adalah: CFI > 0,90 (Bentler, 1990), RMSEA < 0,06, dan SRMR < 0,08 (Hu \& Bentler, 1999). Koefisien $X^{2}$ (chi-square) juga dilaporkan, namun tidak digunakan sebagai kriteria goodness of fit karena nilai ini cenderung menolak model berdasarkan ukuran sampel yang besar (Bentler \& Bonett, 1980).

Pada analisis ini peneliti menguji dua model (gambar 1), yaitu model dua dimensi dominasi dan egalitarian; serta model empat faktor dominasi dan egalitarian dengan pro-trait dan con-trait pada masing-masing dimensinya (D-Pro, DCon, E-Pro, dan E-Con).

Hasil menunjukkan bahwa model dua dimensi tidak fit dengan data $\left(X^{2}\right.$ $(195)=0,000, p<0,001, \mathrm{CFI}=0,832$, RMSEA $=0,136[90 \% \mathrm{Cl} 0,119,0,154]$, SRMR $=0,101$, AIC $=10247)$. Oleh karena itu terdapat dua kemungkinan, pertama model teoretis tidak sesuai dengan data yang diambil, dan kedua, terdapat kekurangan sampel dalam analisis data.

Hasil menunjukkan bahwa model empat faktor fit dengan data $\left(X^{2}(195)=0,000\right.$, $\mathrm{p}<0,001, \mathrm{CFI}=0,961, \mathrm{RMSEA}=0,068$ $[90 \% \mathrm{Cl} 0,044,0,090]$, SRMR $=0,048$, AIC = 10040). Setelah membandingkan kedua model, dapat dilihat bahwa model 2 (SDO 4 Faktor) merupakan model yang fit yang memenuhi kriteria cut-off, atau dengan kata lain model teoretis SDO 4 faktor sesuai dengan data yang diambil. Selain itu, keseluruhan dari faktor loading $(\lambda)$ melewati batas cut-off sebesar 0,35.

\section{Kesimpulan}

Semenjak penemuan teori dominasi sosial (Sidanius dan Pratto, 1999) hampir dua dekade lalu, skala orientasi dominasi sosial ( $\left.\mathrm{SDO}_{1} \mathrm{~S}-\mathrm{SDO}_{7} \mathrm{~S}\right)$ sudah menjadi skala yang sering digunakan untuk mengukur orientasi dominasi sosial dan hubungannya dengan konflik antar kelompok dan ketimpangan sosial. Selain itu $\mathrm{SDO}_{7} \mathrm{~S}$ juga memiliki hubungan yang signifikan dengan konstruk-konstruk lain yang berhubungan dengan fenomena konflik antar kelompok dan ketimpangan sosial, yaitu justifikasi sistem (Jost, 1994; Kay \& Jost, 2003), konservatisme politik (Sidanius dkk., 2008), oposisi terhadap aksi afirmatif (Haley \& Sidanius, 2005), oposisi terhadap kebijakan publik terkait ras (Ho dkk., 2012), oposisi terhadap kesejahteraan (Ho dkk., 2012), rasisme simbolis (Henry \& Sears, 2002), ketimpangan distribusi sumber daya (Ho dkk., 2012), hirarki dalam pekerjaan (Sidanius Pratto, Sinclair, \& Van Laar, 1996), serta anti-black effect (Ho dkk., 2012).

Untuk menangkap keseluruhan dinamika dari fenomena ketimpangan dan konflik antar kelompok, sebaiknya seluruh dimensi dari $\mathrm{SDO}_{7} \mathrm{~S}$ digunakan untuk mendapatkan gambaran utuh. Secara umum, orientasi dominasi sosial dan pengukurannya $\left(\mathrm{SDO}_{7} \mathrm{~S}\right)$ memiliki kekuatan untuk mengukur stratifikasi dan hirarki yang ada dalam sistem sosial. Meskipun dalam adaptasi ini terjadi masalah dalam penentuan item-item yang dapat mengukur orientasi dominasi sosial di Indonesia, namun hasil dari pengukuran pertama menunjukkan bahwa adaptasi dari $\mathrm{SDO}_{7} \mathrm{~S}$ memiliki keberhasilan untuk mengukur orientasi dominasi sosial di Indonesia sesuai dengan postulat dari Sidanius dan Pratto (1999) dalam teori dominasi sosialnya. 


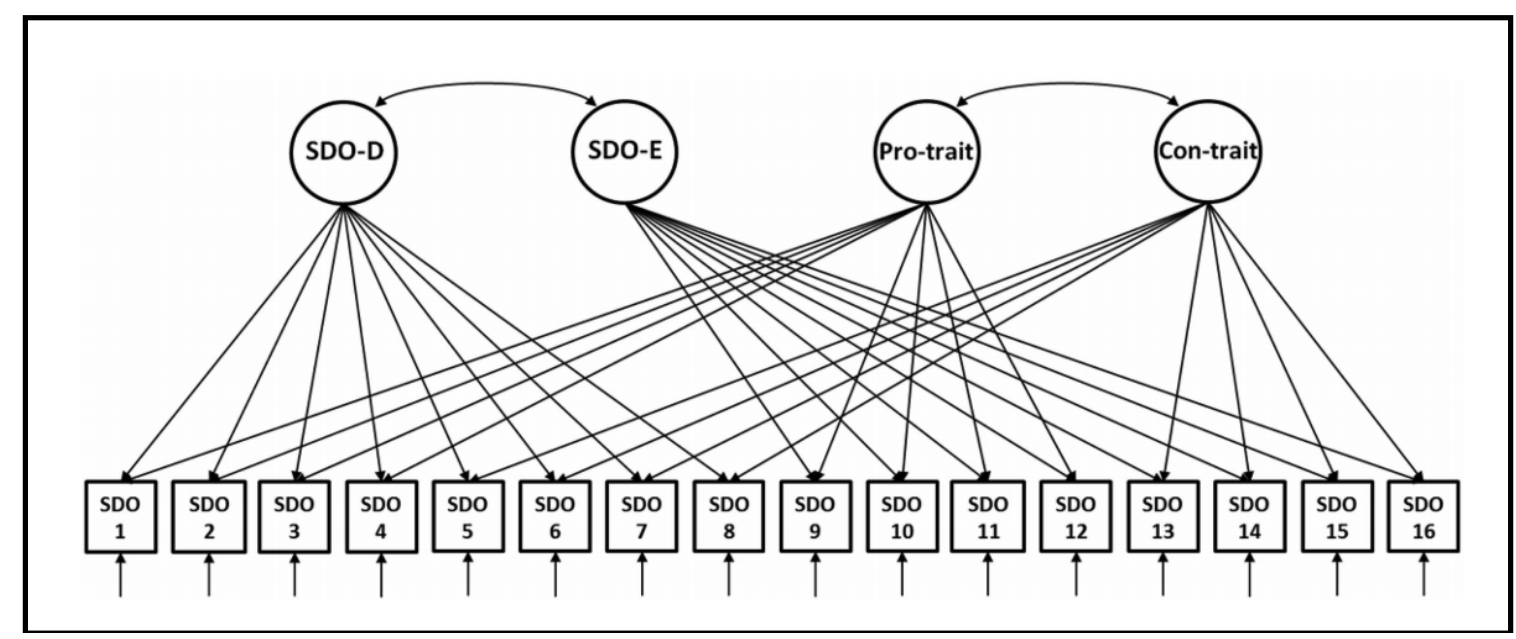

Gambar 1. Empat faktor model analisis faktor konfirmatori (Ho dkk., 2015).

Tabel 6. Analisis Faktor Konfirmatori Model 2 (SDO 4 Faktor)

\begin{tabular}{lcc}
\hline & Factor Loading $(\lambda)$ & Z-value \\
\hline Dominance-Pro & $0.775^{* *}$ & \\
SDO3 & $0,787^{* *}$ & 5,991 \\
SDO4 & $0,888^{* *}$ & \\
Dominance-Con & $0,702^{* *}$ & 11,104 \\
SDO5 & $0,513^{* *}$ & 7,361 \\
SDO6 & $0,667^{* *}$ & 9,322 \\
SDO7 & & \\
SDO8 & $0,682^{* *}$ & \\
Egalitarian-Pro & $0,702^{* *}$ & 8,967 \\
SDO9 & $0,675^{* *}$ & 7,948 \\
SDO10 & $0,712^{* *}$ & \\
SDO11 & \\
SDO12 & $0,9871^{* *}$ & \\
Egalitarian-Con & $0,812^{* *}$ & 17,797 \\
SDO13 & $0,960^{* *}$ & 41,924 \\
SDO14 & $0,802^{* *}$ & 17,126 \\
SDO15 & & \\
SDO16 &
\end{tabular}

**Significant at the 0,01 level.

Secara umum, hasil dari uji alat ukur menunjukkan bahwa alat ukur adaptasi $\mathrm{SDO}_{7} \mathrm{~S}$ merupakan alat ukur yang reliabel dan valid untuk mengukur orientasi dominasi sosial. Hasil uji reliabilitas menunjukkan koefisien alpha sebesar 0.898 yang berarti $89.8 \%$ dari keseluruhan varians merupakan true score (Anastasi \& Urbina, 1997), atau dengan kata lain alat ukur adaptasi $\mathrm{SDO}_{7} \mathrm{~S}$ merupakan alat ukur yang reliabel untuk mengukur orientasi dominasi sosial.

Uji validitas dilakukan dengan melihat konsistensi internal, analisis faktor eksploratori, dan analisis faktor konfirmatori. Hasil menunjukkan bahwa alat ukur adaptasi $\mathrm{SDO}_{7} \mathrm{~S}$ merupakan alat ukur yang valid untuk mengukur orientasi dominasi sosial, namun hanya pada model orientasi dominasi sosial dengan 
empat faktor (Dominasi-Pro, DominasiKon, Egalitarian-Pro, dan EgalitarianKon). Meski begitu, perlu diperhatikan bahwa terdapat dua item yang bermasalah, yaitu item nomor 1 (SDO1) dan item nomor 2 (SDO2). Kedua item ini dikeluarkan dari analisis karena dikhawatirkan akan membuat parameter menjadi tidak reliabel jika disertakan dalam analisis. Penelitian selanjutnya perlu memperhatikan hal ini dan merevisi kedua item yang bermasalah tersebut.

Temuan dari penelitian membuktikan bahwa alat ukur adaptasi $\mathrm{SDO}_{7} \mathrm{~S}$ ke Bahasa Indonesia layak untuk digunakan. Selain itu, peneliti juga membuktikan bahwa orientasi dominasi sosial merupakan konstruk yang dibentuk dari empat faktor; dua dimensi yang masing-masing dimensinya memiliki dua sub-dimensi.

\section{Daftar Pustaka}

Anastasi, A. \& Urbina, S. (1997). Psychological Testing. New Jersey: Prentice-Hall. Inc

Beaton, D. E., Bombardier, C., Guillemin, F., \& Ferraz, M. B. (2000). Guidelines for the process of crosscultural adaptation of self-report measures. SPINE, 25(24), 31863191. doi: 10.1097/00007632200012150-00014

Bentler, P. M. \& Bonett, D. G. (1980). Significance tests and goodness of fit in the analysis of covariance structures. Psychology Bulletin, 88. doi: 10.1037//0033-2909.88.3.588

Bentler, P. M. (1990). Comparative fit indexes in structural models. Psychological Bulletin, 107(2), 238-246. doi: 10.1037//0033-2909.107.2.238

Cohen, R. J. \& Swerdlik, M. (2009). Psychological testing and assessment: An introduction to tests and measurement. New York: McGraw-Hill.

Cruz, F. A., Padilla, G. V., \& Agustin, E. O. (2000). Adapting a measure of acculturation for cross-cultural research. Journal of Transcultural
Nursing, $11(3), \quad 191-198 . \quad$ doi: 10.1177/104365960001100305

Ho, A. K., Sidanius, J., Kteily, N., Sheehy-Skeffington, J., Pratto, F., Henkel, K. E., et al. (2015). The nature of social dominance orientation: Theorizing and measuring preferences for intergroup inequality using the new $\mathrm{SDO}_{7}$ scale. Journal of Personality and Social Psychology, 109(6), 10031028. doi: $10.1037 /$ pspi0000033

Hardin, C. D., \& Higgins, E. T. (1996). Shared reality: How social verification makes the subjective objective. In R. M. Sorrentino \& E. T. Higgins (Eds.), Handbook of motivation and cognition. Handbook of motivation and cognition, Vol. 3. The interpersonal context (pp. 2884). New York, NY, US: Guilford Press.

Henry, P. J., \& Sears, D. O. (2002). The symbolic racism 2000 scale. Political Psychology, 23(2), 253-283. doi: 10.1111/0162-895X.00281

Ho, A. K., Sidanius, J., Pratto, F., Levin, S., Thomsen, L., Kteily, N., et al. (2012). Social dominance orientation: Revisiting the structure and function of a variable predicting social and political attitudes. Personality and Social Psychology Bulletin, 38(5), 583-606. doi: 10.1037/e514892012001

Hu, L. \& Bentler, P. M. (1999). Cut-off criteria for fit indexes in covariance structure analysis: Conventional criteria versus new alternatives. Structural Equational Model Multidisciplinary Journal, 6, 1-55. doi: 10.1080/10705519909540118

Jost, J. T. \& Banaji, M. R. (1994). The role of stereotyping in systemjustification and the production of false consciousness. British Journal of Social Psychology, 33, 1-27. doi: 10.1111/j.2044-8309.1994.tb01008.x Jost, J. T., Banaji, M. R., \& Nosek, B. A. (2004). A decade of system justification theory: Accumulated 
evidence of conscious and unconscious bolstering of the status quo. Political Psychology, 25, 881919. doi: 10.31234/osf.io/6ue35

Jost, J. T., Hawkins, C. B., Nosek, B. A., Hennes, E. P., Stern, C., Gosling, S. D., \& Graham, J. (2014). Belief in just god (and a just society): A system justification perspective on religious ideology. Journal of Theoretical and Philosophical Psychology, 34, 56-81. doi: 10.1037/a0033220

Jost, J. T. \& van der Toorn, J. (2012). System justification theory. In P. A. M. van Lange, A. W. Kruglansi, \& E. T. Higgins (Eds.), Handbook of Theories of Social Psychology (Vol 2, pp. 313-343). London: SAGE.

Moscovici, S. (1984b) 'The Phenomenon of Social Representations', pp. 3-69 in R.M. Farr and S. Moscovici (eds) Social Representations. Cambridge, UK: Cambridge University Press.

Morrison, K. R., Fast, N. J., \& Ybarra, O. (2008). Group status, perceptions of threat, and support for social inequality. Journal of Experimental Social Psychology, 45(1), 204-210. doi: 10.1016/j.jesp.2008.09.004

Pratto, F., Sidanius, J., \& Levin, S. (2006). Social dominance theory and the dynamics of intergroup relations: Taking stock and looking forward. European review of social psychology, 17(1), 271-320. doi: 10.1080/10463280601055772
Pratto, F., Liu, J. H., Levin, S., Sidanius, J., Shih, M., Bachrach, H., \& Hegarty, P. (2000). Social dominance orientation and the legitimization of inequality across cultures. Journal of Cross-Cultural Psychology, 31(3), 369-409. doi: 10.1177/0022022100031003005

Pratto, F., Sidanius, J., Stallworth, L. M., \& Malle, B. F. (1994). Social dominance orientation: A personality variable predicting social and political attitudes. Journal of Personality and Social Psychology, 67 (4), 741-763. doi: $10.1037 / / 0022-3514.67 .4 .741$

Sidanius, J. \& Pratto, F. (1999). Social dominance: An intergroup theory of social hierarchy and oppression. Cambridge University Press: Cambridge.

Sidanius, J., Pratto, F., Sinclair, S., \& Van Laar, C. (1996). Mother Teresa meets Genghis Khan: The dialectics of hierarchy-enhancing and hierarchy-attenuating career choices. Social Justice Research, 9(2), 145170. doi: $10.1007 / B F 02198077$

Zárate, M. A., Garcia, B., Garza, A. A., \& Hitlan, R. T. (2004). Cultural threat and perceived realistic group conflict as dual predictors of prejudice. Journal of Experimental Social Psychology, 40(1), 99-105. doi: 10.1016/s0022-1031(03)00067-2 


\section{APPENDIX}

Tabel A1. Korelasi per Item dengan Item dalam Dimensinya pada Pengukuran Pertama

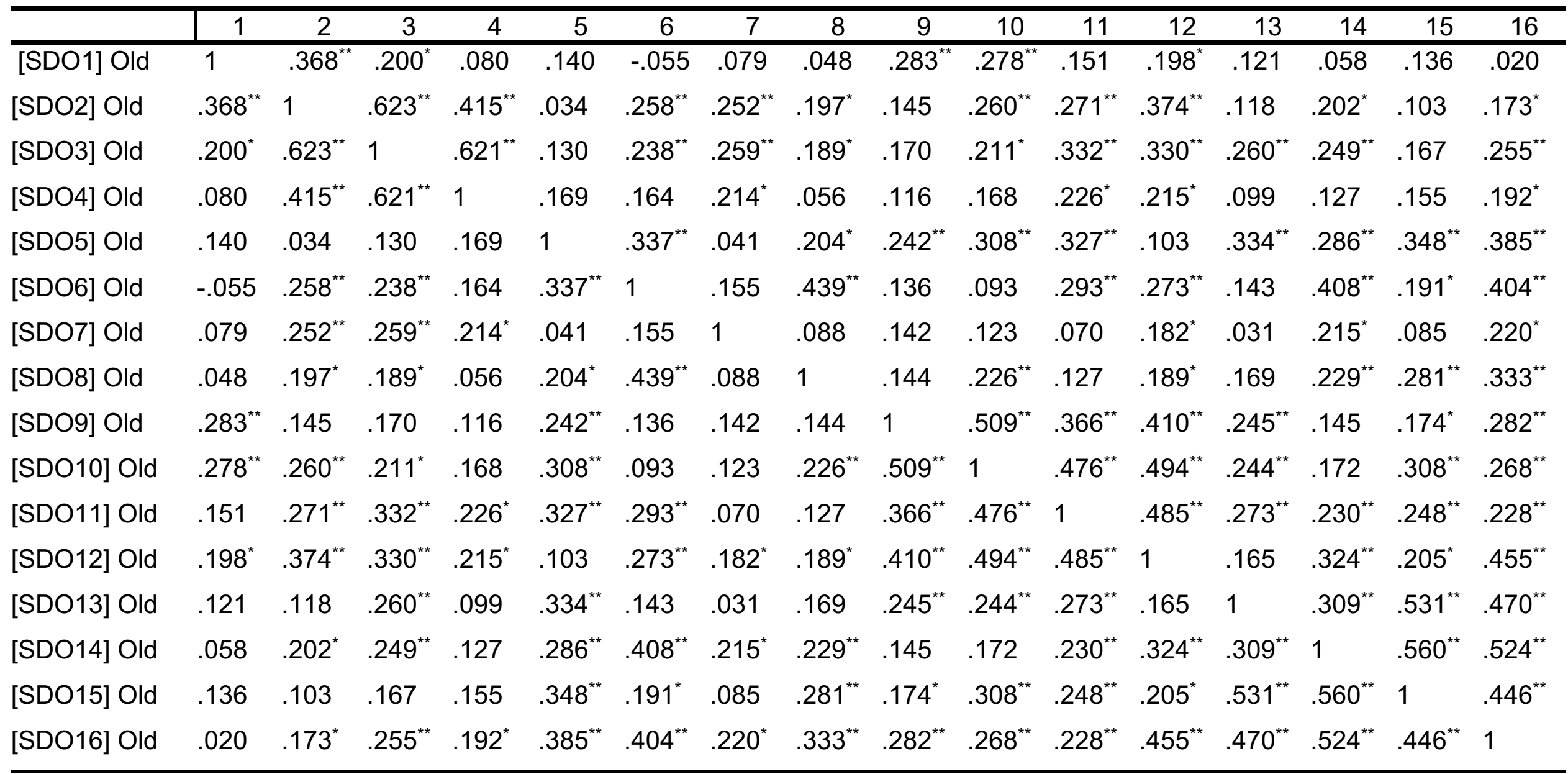

${ }^{* *}$. Correlation is significant at the 0.01 level (2-tailed). *. Correlation is significant at the 0.05 level (2-tailed). 
Tabel A2. Korelasi per Item dengan Item dalam Dimensinya pada Pengukuran Kedua

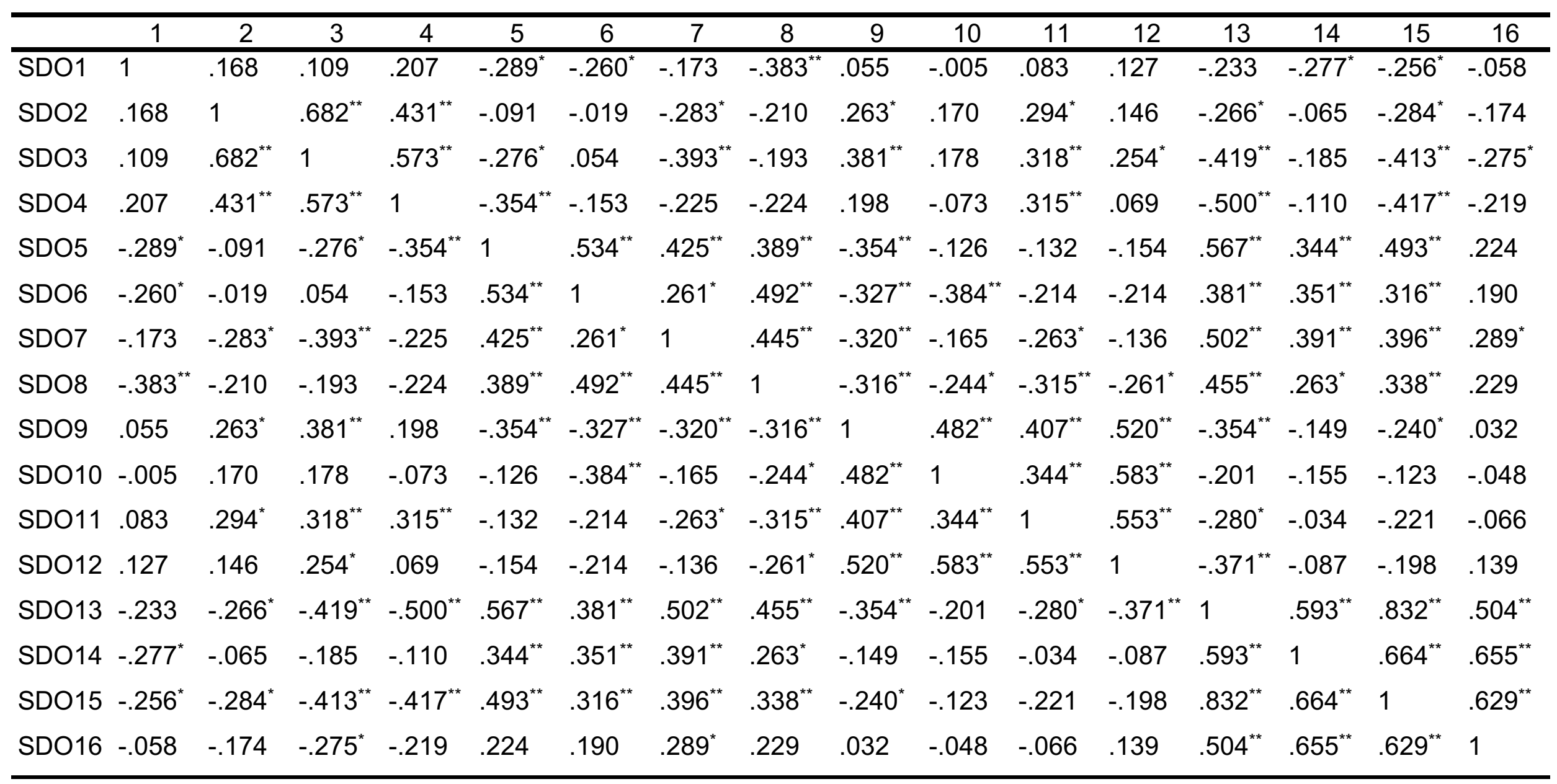

*. Correlation is significant at the 0.05 level (2-tailed). ${ }^{* *}$. Correlation is significant at the 0.01 level (2-tailed). 
Tabel A3. Item-Item Adaptasi SDO 7 S

\begin{tabular}{|c|c|}
\hline Item & Deskripsi \\
\hline SDO1 & $\begin{array}{l}\text { Beberapa kelompok seharusnya tetap berada pada status sosial mereka } \\
\text { masing-masing }\end{array}$ \\
\hline SDO2 & $\begin{array}{l}\text { Mungkin merupakan hal yang baik jika terdapat kelompok tertentu yang } \\
\text { berstatus sosial tinggi dan kelompok lainnya memiliki status sosial rendah }\end{array}$ \\
\hline SDO3 & $\begin{array}{l}\text { Masyarakat yang ideal terdiri atas beberapa kelompok yang berstatus sosial } \\
\text { lebih tinggi dan kelompok lain berstatus sosial lebih rendah }\end{array}$ \\
\hline SDO4 & Beberapa kelompok lebih rendah daripada kelompok-kelompok lainnya \\
\hline $\mathrm{SDO}^{*}$ & $\begin{array}{l}\text { Kelompok yang status sosialnya rendah memiliki hak yang setara dengan } \\
\text { kelompok yang status sosialnya tinggi }\end{array}$ \\
\hline SDO6* & Seharusnya tidak ada satu pun kelompok yang dominan dalam masyarakat \\
\hline $\mathrm{SDO}^{*}$ & $\begin{array}{l}\text { Kelompok-kelompok dengan status sosial rendah tidak seharusnya tetap di } \\
\text { posisi mereka }\end{array}$ \\
\hline SDO8* & $\begin{array}{l}\text { Dominasi suatu kelompok atas kelompok lain adalah sebuah prinsip yang } \\
\text { buruk }\end{array}$ \\
\hline SDO9 & Kita seharusnya tidak mendorong kesetaraan kelompok \\
\hline SDO10 & $\begin{array}{l}\text { Kita seharusnya tidak mengusahakan agar semua kelompok memiliki kualitas } \\
\text { hidup yang sama }\end{array}$ \\
\hline SDO11 & Merupakan sebuah ketidakadilan membuat setiap kelompok menjadi setara \\
\hline SDO12 & Kesetaraan status antar kelompok tidak seharusnya menjadi tujuan utama kita \\
\hline SDO13* & $\begin{array}{l}\text { Kita harus berusaha memberikan kesempatan yang setara pada semua } \\
\text { kelompok masyarakat dalam meraih keberhasilan }\end{array}$ \\
\hline SDO14* & $\begin{array}{l}\text { Kita harus melakukan apapun yang kita mampu untuk menyetarakan kondisi } \\
\text { kelompok yang berbeda-beda }\end{array}$ \\
\hline SDO15* & $\begin{array}{l}\text { Sebesar apapun upaya yang dibutuhkan, kita harus berusaha memastikan } \\
\text { bahwa semua kelompok memiliki kesempatan yang sama dalam hidup }\end{array}$ \\
\hline SDO16* & Kesetaraan antar kelompok seharusnya menjadi cita-cita kita \\
\hline
\end{tabular}

1-7 Likert Scale: Sangat Menolak - Menolak - Agak Menolak - Netral - Agak Mendukung - Mendukung - Sangat Mendukung

Panduan:

Skor total dari alat ukur adaptasi $\mathrm{SDO}_{7} \mathrm{~S}$ adalah penjumlahan dari skor total pada masingmasing dimensi:

D-Pro Total $=$ SDO1 + SDO2 + SDO3 + SDO4

D-Con Total $=$ SDO5 + SDO $6+$ SDO7 + SDO8

E-Pro Total $=$ SDO9 + SDO10 +SDO11 + SDO12

E-Con Total $=$ SDO13 + SDO14 + SDO15 +SDO16

Orientasi Dominasi Sosial $=$ D-Pro Total + D-Con Total + E-Pro Total + E-Con Total 